\title{
FACTORES DE CARGA ÓPTIMOS PARA EL DISEÑO SÍSMICO DE EDIFICIOS
}

\author{
Juan Bojórquez Mora ${ }^{(1)}$, Sonia E. Ruiz Gómez ${ }^{(2)}$
}

\begin{abstract}
RESUMEN
En el presente trabajo se revisan las combinaciones de carga para el diseño de edificaciones que se establecen en el Reglamento de Construcciones del Distrito Federal (RCDF-2004) y sus Normas Técnicas Complementarias (NTC-2004). Se proponen nuevos factores de carga para que se especifiquen en la próxima versión del (RCDF). Se revisa la combinación de carga gravitacional (carga muerta más carga viva) y la combinación de carga por sismo (carga muerta, carga viva y carga por sismo). Se propone una metodología para establecer factores y combinaciones óptimos de carga que garanticen el mínimo costo total esperado durante la vida útil de la estructura y que la probabilidad de falla sea al menos igual a la implícita en el RCDF-2004. Para la estimación de la confiabilidad estructural se hace uso de las Redes Neuronales Artificiales.
\end{abstract}

Palabras clave: combinación de carga; probabilidad de falla; costo total esperado; diseño sísmico; Redes Neuronales Artificiales

\section{OPTIMAL LOAD FACTORS FOR SEISMIC DESIGN OF BUILDINGS}

\begin{abstract}
The load factors and load combinations established in the Mexico City Building Code (MCBC) and its Complementary Technical Standards are revised. New load and resistance factors are proposed to be specified in the next version of the MCBC. The combination of gravitational loads are considered (dead load plus live load) and the combination of earthquake load is also reviewed. A reliabilitybased development of load factors for the combination of seismic and gravity loads is presented. The procedure aims at minimizing the total expected life-cycle cost of buildings having a minimum value of probability of failure equal to the implicit probability in the MCBC. The structural reliability is estimated using Artificial Neural Networks.
\end{abstract}

Keywords: load combination; failure probability; total expected cost; seismic design; Artificial Neural Networks

Artículo ganador del Décimo Concurso Nacional de Tesis de Doctorado 2017 organizado por la SMIS. Se aceptarán comentarios y/o discusiones hasta cinco meses después de su publicación.

(1) Facultad de Ingeniería, Universidad Autónoma de Sinaloa, Calzada de las Américas y Boulevard Universitarios S/N, Ciudad Universitaria, Culiacán, Sinaloa, México, C.P. 80040.juanbm@uas.edu.mx jbm_squall_cloud@hotmail.com

(2) Instituto de Ingeniería, Universidad Nacional Autónoma de México, Coyoacán, C.P. 04510, México, D.F. sruizg@iingen.unam.mx 


\section{INTRODUCCIÓN}

Las Normas Técnicas Complementarias sobre Criterios y Acciones para el Diseño Estructural de las Edificaciones del Reglamento de Construcciones para el Distrito Federal especifican que la seguridad de una estructura deberá verificarse para el efecto combinado de acciones permanentes, variables y accidentales. Las NTCCA-2004 también recomiendan que los efectos de todas las acciones deberán multiplicarse por un factor de carga igual a 1.1 aplicado a los efectos de todas las acciones que intervengan en la combinación; es decir, para revisar los efectos en estructuras en donde se incluyan movimientos sísmicos se considera la combinación $1.1 \mathrm{C}_{\mathrm{m}}+1.1 \mathrm{C}_{\mathrm{v}}+1.1 \mathrm{~S}$, donde $\mathrm{C}_{\mathrm{m}}=$ Carga muerta, $\mathrm{C}_{\mathrm{v}}=$ Carga viva, $\mathrm{S}$ = sismo. Los factores de carga (1.1) que multiplican a $\mathrm{C}_{\mathrm{m}}, \mathrm{C}_{\mathrm{v}}$ y $\mathrm{S}$ están basados en estudios breves y en el criterio de reconocidos investigadores e ingenieros estructuristas. El presente estudio pretende dar una fundamentación a estos valores o bien modificarlos con base en un criterio de optimización. Aquí se propone y aplica un criterio para encontrar la combinación óptima de factores de carga que incluya los efectos de cargas muerta, viva y sismo $\left(\mathrm{C}_{\mathrm{m}}+\mathrm{C}_{\mathrm{v}}+\mathrm{S}\right)$ de manera que el costo total sea mínimo y que la probabilidad de falla estructural sea al menos igual a la implícita en el RCDF-2004. El criterio de optimización propuesto se aplica tanto a edificios de concreto reforzado como de acero, localizados en la zona IIIb del valle de México. Para ello se realizó un levantamiento general de edificios a base de marcos de concreto reforzado y de acero, ubicados en la zona IIIb del valle.

El diseño estructural ha ido cambiando y mejorando continuamente, hoy en día, la gran mayoría de códigos del mundo han intentado establecer criterios de diseños basados en confiabilidad, esto con el fin de mejorar el comportamiento estructural, de reducir los daños y reducir los costos a valores aceptables (Sorensen et al., 1994; Wen, 2001; Ellingwood, 1994a, 1994b; Bojórquez et al., 2017). Existen diversas formas para calibrar los códigos de diseño. Gayton et al., 2004 describen algunos métodos utilizados comúnmente, este trabajo se enfoca a evaluar el costo total esperado durante la vida útil de los edificios. Evaluar el costo total esperado durante la vida útil de las estructuras es actualmente un gran reto para los ingenieros civiles debido a que las estructuras son diseñadas para que tengan una vida útil relativamente amplia, aproximadamente entre 50 y 75 años (American Society of Civil Engineers ASCE, 2010). Este tema ha sido ampliamente estudiado en las últimas décadas por diversos autores como, por ejemplo: Akta et al., 2001; Ang, 2011; Mitropoulou et al., 2011; Lagaros, 2007; Wen y Kang, 2001a, 2001b; Baron y Frangopol, 2015; Esteva et al., 2011; Montiel y Ruiz, 2007; sin embargo, estás metodologías están generalmente limitadas a la aplicación de algunos ejemplos particulares. El costo total, como se trata aquí, incluye el costo inicial y el costo por daños causados por futuros sismos. El valor presente del costo incluye diferentes costos. Estos son: costo inicial, costo por reparación, costo de daño al contenido, costo asociado a la pérdida de vidas humanas, costo por heridas y pérdidas económicas.

En el presente trabajo se propone una metodología para establecer factores y combinaciones óptimos de carga que garanticen el mínimo costo total esperado durante la vida útil de la estructura considerando miles de estructuras, y para realizar esta tarea se hace uso de herramientas de inteligencia artificial. Para evaluar el desempeño estructural se utilizan análisis probabilísticos y se considera que la ocurrencia de los sismos es un proceso de Poisson (Wang et al., 2014). Se aplica el método de integración para obtener las tasas anuales de excedencia de un cierto nivel de distorsión máxima de entrepiso dada una intensidad sísmica. Se simulan demandas sísmicas a partir de la curva de peligro de demanda de distorsión máxima de entrepiso. La simulación se realiza mediante el método de simulación inversa (Rubinstein, 1981). Para el análisis se usan 31 movimientos originados por eventos intensos ( $\mathrm{M}>6.0)$ ocurridos en la zona de subducción del Pacífico Mexicano y registrados en diferentes estaciones ubicadas en la zona IIIb del valle de México. La metodología se aplica a edificios de acero y de C/R de 4 a 20 niveles. Para obtener la respuesta de un gran número de edificios se utiliza la técnica de Redes Neuronales Artificiales. Como resultado final se proponen combinaciones de valores adecuados de factores de carga muerta, viva y sismo que son aplicables a diseños correspondientes a la zona IIIb del valle de México. 


\section{METODOLOGÍA}

Los pasos generales que se siguen en el presente estudio son los siguientes:

1. Se diseñan diferentes edificios de $\mathrm{C} / \mathrm{R}$, y alternativamente de acero, de acuerdo con las especificaciones del Reglamento de Construcciones del Distrito Federal. Los edificios se diseñan usando diferentes combinaciones de carga.

2. Se obtiene la distorsión máxima de entrepiso asociada a los estados límites de interés, mediante análisis dinámicos incrementales (ADI), (Vamvatsikos y Cornell, 2002).

3. Para cada combinación de cargas de diseño, y aplicando la ec. 1 (Cornell, 1968; Esteva, 1968), se determinan las tasas anuales de excedencia de cierto nivel de distorsión (curva de peligro de demanda de distorsión máxima de entrepiso):

$v_{D}(d)=\int \frac{d v\left(S_{a}\right)}{d\left(S_{a}\right)} P\left(D \geq d S_{a}\right) d\left(S_{a}\right)$

donde:

$d$ representa la distorsión máxima de entrepiso

$v_{D}(d)$ es el número de veces por año que se excede $d$

$S_{a}$ es la ordenada del espectro de seudoaceleraciones

$P\left(D \geq d \mid S_{a}\right)$ representa la curva de vulnerabilidad. Es la probabilidad de que el valor $D$ en una estructura exceda la distorsión $d$, dada una intensidad $S_{a}$

$v\left(S_{a}\right)$ es el número medio de veces por año que ocurre una intensidad igual o mayor que $S_{a}$. Esta función representa la curva de peligro sísmico del sitio de interés.

4. Posteriormente se calcula la probabilidad de falla anual para cada combinación, utilizando la ec. 2 (Cornell, 2002; Montiel y Ruiz, 2007).

$v_{f}=\int\left|\frac{d v_{D}(d)}{d(d)}\right| p(C \leq D) d(d)$

donde:

$v_{f}$ es el número de veces por año que la demanda $D$ excede a la capacidad $C$

$p(C \leq D)$ es la función de distribución acumulada de la capacidad

5. Se descartan las combinaciones de factores de carga utilizadas en los diseños de edificios que presenten una tasa media anual de falla estructural mayor que la implícita en el Reglamento de Construcciones de la Ciudad de México $\left(v_{0, M C B C-04}\right)$; es decir, se establece la siguiente condición:

$v_{f}(\gamma) \leq\left(v_{0, M C B C-04}\right)$ 
6. A partir de las demandas sísmicas simuladas se calcula el índice de daño que presentan las estructuras. Con ello es posible calcular los costos totales, los que deben transportarse a valor presente con la siguiente expresión:

$V P=\frac{V F}{(1+i)^{n}}$

donde:

$V P$ es el valor en el tiempo en el tiempo 0 (es decir, el presente)

$V F$ es el valor en el tiempo $n$ (futuro)

$i$ es la tasa bajo la cual el dinero será aumentado a través del tiempo

$n$ es el año a evaluar

7. Para cada combinación de carga se estima el costo total esperado $\left(C_{T}\right)$ asociado a la vida útil de la estructura (en el presente estudio se supone que los edificios tienen una vida útil de 50 años), de la siguiente manera:

$C_{T}(\gamma)=C_{I}(\gamma)+C_{d}(\gamma)$

donde:

$C_{T}$ representa el costo total esperado por metro cuadrado de edificio

$C_{I}$ es el costo inicial

$C_{d}$ es el costo asociado a los daños estructurales

$\gamma$ corresponde a cada una de las combinaciones de cargas de diseño

El costo total causado por sismos $\left(C_{T D S}\right)$ para un grupo de edificios ubicados en una determinada región asociado a cierta combinación de carga se estima suponiendo que las estructuras del grupo sufrirán demandas estructurales similares. Por lo tanto, el $C_{T D S}$ en una región se supone igual a la suma de los costos totales durante la vida útil de cada edificio $\left(M_{i}\right)$ ubicado en dicha zona. La expresión para estimar dicho costo es (Bojórquez et al., 2017):

$C_{t d s}\left(\gamma_{i}\right)=\sum C_{t}\left(\gamma_{i}\right)\left(M_{i}\right)$

donde $C_{t d s}\left(\gamma_{i}\right)$ : costo total por daño causado por sismo; $C_{t}\left(\gamma_{i}\right)\left(M_{i}\right)$ : costo total durante la vida útil del edificio $M_{i}$; y $\gamma_{i}$ : combinación de carga con la que se diseña el edificio. Finalmente, se deduce la combinación óptima que deben tener los factores de carga muerta, carga viva y de carga por sismo, de manera que el costo total esperado de la construcción sea el mínimo:

$\min \left[C_{t d s}\left(\gamma_{i}\right)\right]$

\section{COSTO TOTAL EN LA VIDA ÚTIL DE LA ESTRUCTURA}

El costo total está integrado por el costo inicial $\left(\mathrm{C}_{\mathrm{i}}\right)$, costo de reparación por daños $\left(\mathrm{C}_{\mathrm{d}}\right)$ y los costos sociales $\left(\mathrm{C}_{\mathrm{s}}\right)$ que ocurren durante la vida útil de la estructura. De esta forma, el costo total asociado a una combinación de factores de carga $(\gamma)$, está dado por la siguiente expresión: 


$$
C_{t}(\gamma)=C_{i}(\gamma)+C_{d}(\gamma)+C_{s}(\gamma)
$$

El costo de reparación por daños y los costos sociales se estiman a partir de una medida de daño físico, y se establece mediante un índice de daño, $I D$, que toma valores entre 0 y 1 . Así, para el caso de daño total el $I D$ es igual a 1, mientras que cuando no existe daño el $I D$ es igual a 0 . El $I D$ se define con la ec. 9 (Tolentino y Ruiz, 2013):

$I D=\frac{\delta_{d}-\delta_{y}}{\delta_{u}-\delta_{y}}$

donde $\delta_{d}$ : distorsión de demanda máxima de entrepiso en la estructura; $\delta_{y}$ : distorsión máxima de entrepiso asociado al estado límite de servicio (estructura sin daño); y $\delta_{u}$ : Es la distorsión máxima de entrepiso asociada al estado límite de colapso. Los valores $\delta_{y}$ y $\delta_{u}$ se obtienen de las estadísticas (valor esperado) de los resultados de los análisis dinámicos incrementales, mientras que el valor $\delta_{d}$ es el que se obtiene de la simulación de las demandas estructurales a partir de la curva de peligro de demanda sísmica en un periodo de tiempo en específico.

\section{Costo inicial}

El costo inicial $\left(\mathrm{C}_{\mathrm{i}}\right)$ está integrado por el costo directo, indirecto y la utilidad, que se pagan al constructor. Este costo se estima a partir de los costos de los materiales (concreto y acero) utilizando la ec. 10 (Velázquez, 2015). En donde $C_{m}$ es el costo de los materiales.

$C_{i}=1.93 C_{m}$

En este trabajo se considera que el costo unitario del concreto $\left(\mathrm{f}^{\prime} \mathrm{c}=250 \mathrm{~kg} / \mathrm{cm}^{2}\right.$ ) es $2000 \$ / \mathrm{m}^{3}$, mientras que el costo unitario del acero es $13 \$ / \mathrm{kg}$. Estos costos se obtienen de un promedio de precios cotizados en México.

\section{Costo de reparación por daños}

El costo por daño $\left(\mathrm{C}_{\mathrm{d}}\right)$ en una estructura durante su vida útil se puede considerar como la suma de los siguientes costos: por reparación o por reconstrucción $\left(\mathrm{C}_{\mathrm{pr}}\right)$ y por pérdida de contenido $\left(\mathrm{C}_{\mathrm{pc}}\right)$. Entonces el costo de reparación por daños se expresa como:

$C_{d}=C_{p r}+C_{p c}$

\section{a) Costo por reparación o por reconstrucción}

En muchas ocasiones los daños son muy severos, y por seguridad es necesario demoler la estructura. De León y Ang (1995) establecen que a partir de un $I D>0.7$ en estructuras de concreto la reparación ya no se puede llevar a cabo, por lo que es necesario demoler. Cuando el $I D>0.7$ el costo máximo por reconstrucción (incluye demolición, limpieza y rediseño) de la estructura se estima como un $20 \%$ adicional del costo inicial $\left(C_{i}\right)$ mientras que, para índices de daños menores, el costo por reparación está en función del costo inicial y del $I D$ elevado a la segunda potencia. Así, el costo por reparación considerando el encamisado de los miembros estructurales o costo por reconstrucción se define con la ec. 12 (Bojórquez et al., 2015): 


$$
C_{p r}=\left\{\begin{array}{c}
C_{i}\left(I D^{2}\right) ; 0<I D<0.7 \\
1.2\left(C_{i}\right) ; I D \geq 0.7
\end{array}\right.
$$

\section{b) Costo por pérdida de contenido}

El costo por pérdida de contenidos por movimientos sísmicos puede tener mayor importancia dependiendo del uso que tiene la estructura, debido a que los contenidos en un hospital no tienen el mismo valor económico que los contenidos de un edificio de oficinas o el de un hotel. En este estudio el costo máximo por pérdida de contenidos $(I D \geq 1)$ es una fracción del costo inicial del edificio, adoptándose una fracción del 50\% (Surahman y Rojaniani, 1983). Para el caso de $I D<1$ se considera una variación del costo en función del $I D$ de forma lineal. Así, el costo por contenidos se define con la ec. 13 (De León, 1991):

$C_{p c}=\left\{\begin{array}{c}0.5\left(C_{i}\right)(I D) ; 0<I D<1 \\ 0.5\left(C_{i}\right) ; I D \geq 1\end{array}\right.$

\section{Costos sociales}

En los costos sociales se incluye el costo por pérdida económica $\left(\mathrm{C}_{\mathrm{pe}}\right)$, pérdida de vidas $\left(\mathrm{C}_{\mathrm{pv}}\right)$ y por lesiones $\left(\mathrm{C}_{\mathrm{pl}}\right)$. Entonces los costos sociales se definen como:

$C_{s}=C_{p e}+C_{p v}+C_{p l}$

\section{a) Costo por pérdida económica}

El costo por pérdidas económicas $\left(C_{p e}\right)$ depende del tipo de uso que tenga la estructura. En este estudio se analizan edificios que tienen uso de oficinas, por lo que las pérdidas económicas se asocian a no generar dinero debido al concepto de renta durante el tiempo en que la estructura es reparada o reconstruida. Este costo máximo por pérdidas económicas $(I D \geq 1)$ está en función del periodo máximo de reconstrucción $\left(P_{r}\right)$, del área del edificio en metros cuadrados $(A)$ y del costo por metro cuadrado de renta al mes $(R)$. Así, el costo por pérdidas económicas se estima utilizando la ec. 15 (De León, 1991; ver tabla 1). Para el caso de $I D<1$ se supone una variación del costo en función del $I D$ elevado a la segunda potencia. Con base en lo anterior, para la estimación del costo por pérdidas económicas, se considera que la renta promedio $(R)$ de una oficina en la ciudad de México es igual a $250 \$ / \mathrm{m}^{2}$ al mes (Granados, 2015) y que el periodo máximo de reconstrucción $\left(P_{r}\right)$ de un edificio es igual a 24 meses.

\section{b) Costo por pérdida de vidas}

Estimar el costo por pérdida de vidas, es una tarea difícil debido a que es un tema subjetivo, es decir, pueden tomarse diferentes criterios para tratar de estimar este costo. En este estudio el costo por pérdida de vida se estima considerando el ingreso anual de cada persona. Por otra parte, para poder determinar el costo por pérdida de vidas es necesario estimar el número medio de personas fallecidas dentro de un área de construcción, durante eventos sísmicos intensos. Para ello, se emplea una regresión no lineal para estimar el número de muertos $\left(N_{d}\right)$ en función del área colapsada. Esta regresión se obtuvo con base en el área total de los edificios colapsados en la Ciudad de México durante el sismo de 1985 (Instituto de Ingeniería UNAM, 1985) y en el número de fallecidos (Tokyo Metropolitan Government, 1985). Así, $N_{d}$ se define con la siguiente expresión: 


$$
N_{d}=\frac{995.3 A^{2.34}}{188+A^{2.34}}
$$

donde $A$ es el área del edificio colapsado en $1000 \mathrm{~m}^{2}$.

Bojórquez et al., (2017) supone que, para el caso de colapso incipiente el número de muertos por unidad de área colapsada $\left(N_{d}\right)$, representa el $75 \%$ de las personas que están dentro del edificio y que sólo el $5 \%$ de las personas dentro del edificio mueren, es decir, $N_{d}$ representa el número de muertos para un caso extremo. En este estudio se considera el caso de colapso incipiente. El número de muertos ante colapso incipiente está dado por la siguiente expresión:

$$
N_{m}=\frac{0.05 N_{d}}{0.75}
$$

El costo máximo por pérdida de vidas $(I D \geq 1)$ es igual al número de muertos ante colapso incipiente multiplicado por el valor esperado de sus ingresos durante su vida laboral. Se considera que el ingreso anual promedio de una persona en México es igual a $\$ 156,000$ (INEGI), y que la vida laboral útil por individuo es igual a 25 años, así el costo por fallecimiento $\left(C_{p f}\right)$ de una persona es igual a $\$ 3,900,000$, por lo tanto, el costo por pérdida de vidas $\left(C_{p v}\right)$ se define con la ec. 18 (De León, 1991; ver tabla 1). Para $I D<1$ se supone una variación del costo en función del ID elevado a la cuarta potencia.

\section{c) Costo por lesiones}

La evaluación del costo por lesiones $\left(C_{p l}\right)$ se refiere a los costos involucrados durante las estadías en el hospital de las personas que resultan heridas ante un terremoto. De León, (1991) estimó el número medio de personas heridas por unidad de área colapsada de los edificios resultando este valor igual a $0.0168 / \mathrm{m}^{2}$, esta cantidad es el resultado de dividir el número de heridos reportados en el sismo de 1985 que afectó a la Ciudad de México (Tokyo Metropolitan Government, 1985) entre el área total de los edificios colapsados (Instituto de Ingeniería UNAM, 1985). Por otra parte, el costo por lesiones sin incapacidad $\left(C_{s i}\right)$ se considera igual a \$23,000 (Tokyo Metropolitan Government, 1985). El costo por lesiones con incapacidad $\left(C_{c i}\right)$ se supone que es $\$ 3,900,000$ (igual al costo por fallecimiento). Tomando en cuenta lo anterior, el costo máximo por lesiones $(I D \geq 1)$ está dado por la ec. 19 (De León, 1991; ver tabla 1), en donde se considera el número de personas con incapacidad es igual al 10\% del total del número de heridos, mientras que el $90 \%$ restante tienen lesiones $\sin$ incapacidad. Para $I D<1$ se supone una variación del costo en función del $I D$ elevado a la segunda potencia. En la tabla 1 se resumen las ecs. para estimar los costos sociales.

Tabla 1. Costos sociales

\begin{tabular}{cccc}
\hline Costo & $0<I D<1$ & $I D \geq 1$ & ec. \\
\hline $\begin{array}{c}\text { Por pérdida } \\
\text { económica } \\
\begin{array}{c}\text { Por pérdida de } \\
\text { vidas }\end{array}\end{array}$ & $C_{p e}=R\left(P_{r}\right)(A)\left(I D^{2}\right)$ & $C_{p e}=R\left(P_{r}\right)(A)$ & 15 \\
Por lesiones & $C_{p v}=N_{m}\left(C_{p f}\right)\left(I D^{4}\right)$ & $C_{p v}=N_{m}\left(C_{p f}\right)$ & 18 \\
\hline
\end{tabular}

Los costos antes descritos deben transportarse al valor presente utilizando la ec. 20:

$$
V P=\frac{V F}{(1+i)^{n}}
$$


donde $V P$ : valor en el tiempo 0 (es decir, el presente); $V F$ : valor en el tiempo $n$ (futuro); $i$ : tasa de descuento; y $n$ : número de años a ser considerados.

\section{CARACTERÍSTICAS DE LA ZONA DE ESTUDIO}

\section{Movimientos sísmicos}

Para analizar los edificios se seleccionaron los 31 acelerogramas registrados en las estaciones del valle de México que se indican en la tabla 2. Las estaciones se ubican en la Zona IIIb según la zonificación sísmica de las Normas Técnicas Complementarias para Diseño por Sismo (NTCDS-2004) del RCDF. Las características principales de los eventos sísmicos se muestran en la tabla 2. Con el fin de contar con diferentes intensidades sísmicas, los registros se multiplicaron por diferentes factores de escala. Dichos factores son la relación que existe entre la pseudoaceleración correspondiente al periodo de vibración del sistema en estudio y la pseudoaceleración correspondiente a la intensidad a la que se desea escalar el movimiento (Shome y Cornell, 1999; Chan et al., 2005). El factor se multiplica por la historia completa de aceleraciones del registro en estudio. Las curvas de peligro sísmico que se utilizan en este trabajo corresponden al sitio de la Secretaria de Comunicaciones y Transportes (SCT).

Tabla 2. Características de los eventos sísmicos

\begin{tabular}{|c|c|c|c|}
\hline FECHA DEL SISMO & $\begin{array}{l}\text { COORDENADA DEL } \\
\text { EPICENTRO }\end{array}$ & MAGNITUD & ESTACIÓN \\
\hline $97-01-11$ & $17.910 \mathrm{~N} ; 103.04 \mathrm{~W}$ & 6.9 & VALLE GÓMEZ \\
\hline $95-10-09$ & $18.74 \mathrm{~N} ; 104.67 \mathrm{~W}$ & 7.3 & VALLE GÓMEZ \\
\hline $89-04-25$ & $16.603 ; 99.400$ & 6.9 & TLATELOLCO \\
\hline $95-09-14$ & $16.31 ; 98.88$ & 7.4 & TLATELOLCO \\
\hline $97-01-11$ & $17.91 ; 103.04$ & 6.9 & TLATELOLCO \\
\hline $89-04-25$ & $16.603 ; 99.400$ & 6.9 & GARIBALDI \\
\hline $95-09-14$ & $16.31 ; 98.88$ & 7.2 & GARIBALDI \\
\hline $95-10-09$ & $18.74 ; 104.67$ & 7.3 & GARIBALDI \\
\hline $97-01-11$ & $17.9 ; 103$ & 6.9 & GARIBALDI \\
\hline $95-09-14$ & $16.31 ; 98.88$ & 7.2 & ALAMEDA \\
\hline $89-04-25$ & $16.603 ; 99.4$ & 6.9 & ALAMEDA \\
\hline $89-04-25$ & $16.603 ; 99.4$ & 6.9 & TLATELOLCO \\
\hline $95-09-14$ & $16.31 ; 98.88$ & 7.2 & TLATELOLCO \\
\hline $95-10-09$ & $18.74 ; 104.67$ & 7.3 & LIVERPOOL \\
\hline $97-01-11$ & $17.9 ; 103$ & 6.9 & LIVERPOOL \\
\hline $95-09-14$ & $16.31 ; 98.88$ & 7.2 & CORDOBA \\
\hline $95-10-09$ & $18.74 ; 104.67$ & 7.3 & CORDOBA \\
\hline $97-01-11$ & $17.9 ; 103$ & 6.9 & CORDOBA \\
\hline $89-04-25$ & $16.603 ; 99.4$ & 6.9 & C.U. JUAREZ \\
\hline $95-09-14$ & $16.31 ; 98.88$ & 7.2 & C.U. JUAREZ \\
\hline $95-10-09$ & $18.74 ; 104.67$ & 7.3 & C.U. JUAREZ \\
\hline $97-01-11$ & $17.91 ; 103.04$ & 6.9 & C.U. JUAREZ \\
\hline $95-09-14$ & $16.31 ; 98.88$ & 7.2 & CUJP \\
\hline $95-10-09$ & $18.74 ; 104.67$ & 7.3 & CUJP \\
\hline $97-01-11$ & $17.9 ; 103$ & 6.9 & CUJP \\
\hline $85-09-19$ & $18.08 ; 102.942$ & 8.1 & SCT B-1 \\
\hline $89-04-25$ & $16.603 ; 99.4$ & 6.9 & SCT B-2 \\
\hline $89-04-25$ & $16.603 ; 99.4$ & 6.9 & SECTOR POPULAR \\
\hline $95-09-14$ & $16.31 ; 98.88$ & 7.2 & SECTOR POPULAR \\
\hline $95-10-09$ & $18.74 ; 104.67$ & 7.3 & SECTOR POPULAR \\
\hline $97-01-11$ & $17.91 ; 103.04$ & 6.9 & SECTOR POPULAR \\
\hline
\end{tabular}




\section{Levantamiento de edificios existentes en la zona de estudio}

Para poder generalizar los resultados con la metodología propuesta fue necesario hacer un levantamiento de todos los edificios ubicados en la Zona IIIb del valle de México, y realizar un análisis de costo durante la vida útil de cada uno de los edificios utilizando la ec. 5; sin embargo, esta tarea requiere de bastante tiempo de cómputo. Para simplificar el análisis en este trabajo se consideran edificios de concreto reforzado o bien de acero, que son regulares. También se supone que los edificios menores a 3 niveles no sufrirán daños significativos debido a que el periodo fundamental de estos se encuentra lejos del periodo con ordenada máxima del espectro de respuesta medio. Además, se considera que los edificios con más de 18 niveles pertenecen a un solo grupo ya que su periodo fundamental es mayor que el periodo con ordenada máxima del espectro de respuesta medio. En la figs. 1 y 2 se muestra el levantamiento de todos los edificios con las características antes mencionadas, ubicados en la Zona IIIb con periodos dominantes del suelo entre 1.5 y 2.0s del valle de México (Velázquez, 2015). Los edificios se agruparon en función del número de niveles, debido a que generalmente los edificios con altura similar se encontraban muy cercanos entre sí, por ejemplo, en conjuntos habitacionales. Se encontró que existen aproximadamente 140 mil edificios desplantados en esta zona de los cuales más de 134 mil tienen menos de 3 niveles. El número estimado de edificios de $\mathrm{C} / \mathrm{R}$ y de acero se muestra en la tabla 3.

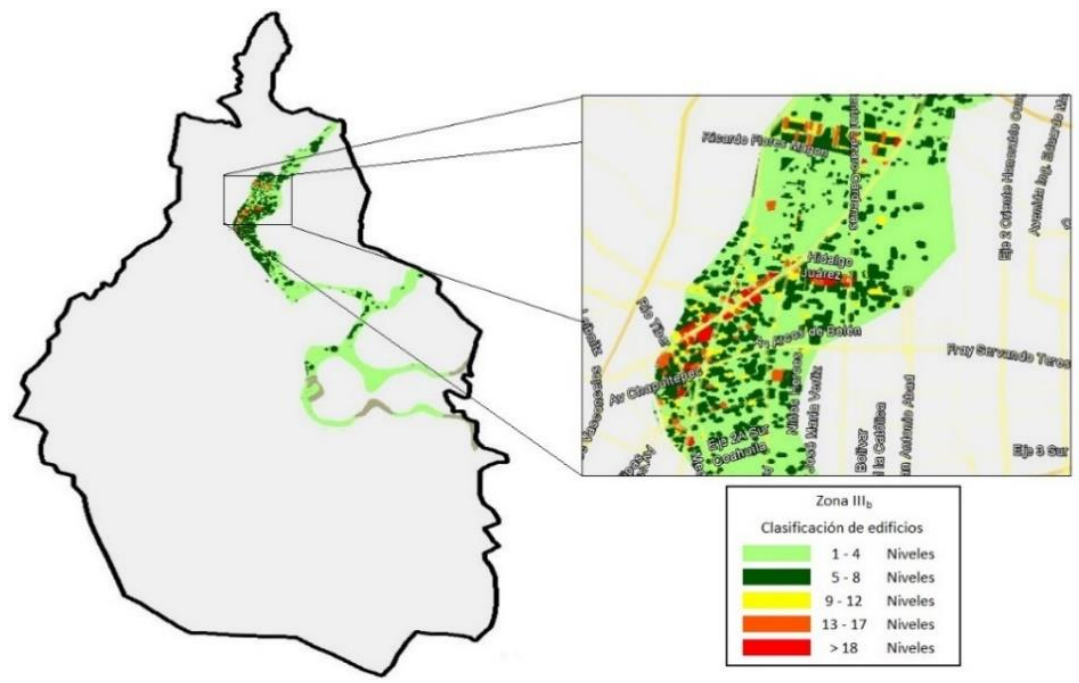

Figura 1. Mapa de la distribución de edificios en la Zona IIIb

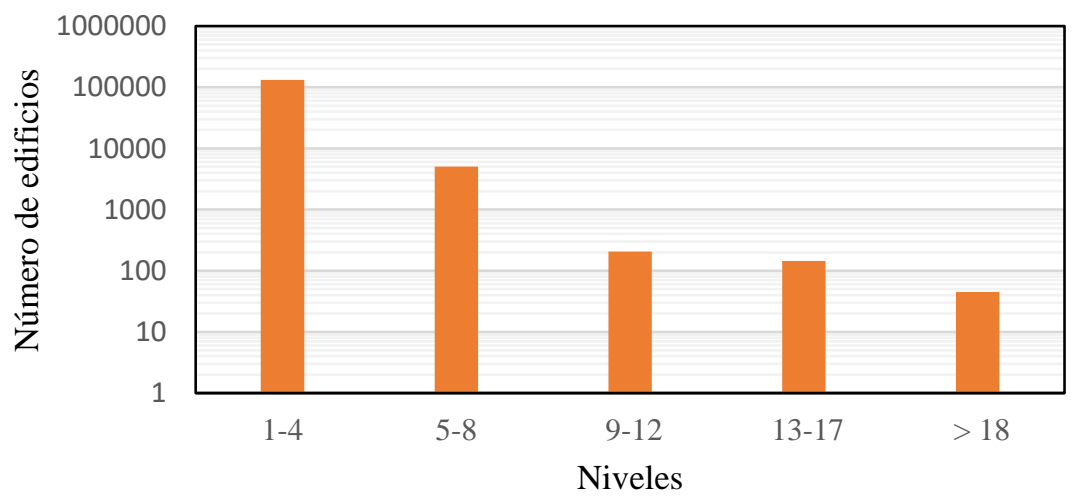

Figura 2. Histograma de número de edificios ubicados en la Zona IIIb 
Tabla 3. Número estimado de edificios de $\mathrm{C} / \mathrm{R}$ y de acero

\begin{tabular}{cccc}
\hline Grupo & Niveles & $\begin{array}{c}\text { Número de } \\
\text { edificios de C/R }\end{array}$ & $\begin{array}{c}\text { Número de } \\
\text { edificios de acero }\end{array}$ \\
\hline 1 & $1-4$ & 109093 & 22273 \\
2 & $5-8$ & 4045 & 1011 \\
3 & $9-12$ & 152 & 53 \\
4 & $13-17$ & 84 & 60 \\
5 & $>18$ & 15 & 30 \\
\hline
\end{tabular}

Para evaluar la ec. 7 considerando todos los edificios ubicados en la Zona IIIb se hace uso de la teoría de Redes Neuronales Artificiales. Bojórquez et al., (2014) demostraron que es posible obtener el diseño y la respuesta de edificios regulares de C/R utilizando la teoría de las RNA. En este estudio se utilizó dicho modelo para obtener los diseños de todo el conjunto de edificios. Además, se elaboró otro modelo de RNA que estima la curva de peligro de demanda estructural, así como también la curva de capacidad estructural de cada uno de los edificios (Bojórquez et al., 2015). La base de datos para entrenar los edificios se obtuvo de estudios previos, así como también de los diseños realizados en este estudio. Los modelos de RNA presentaron un porcentaje de error no mayor que el $15 \%$ en los edificios estudiados durante el entrenamiento.

\section{CARACTERÍSTICAS DE LOS EDIFICOS ESTUDIADOS}

\section{Edificios de concreto reforzado}

Se analizan 14 edificios de concreto reforzado de 4, 6, 8, 10, 12, 15 y 20 niveles. Para los modelos de los edificios se utilizó un factor de comportamiento sísmico $Q=3$. Las distorsiones de entrepiso de los edificios de $\mathrm{C} / \mathrm{R}$ se limitaron a $\delta / \mathrm{h}=0.03$ para colapso, y $\delta / \mathrm{h}=0.004$ para servicio, donde $\delta$ es el desplazamiento y h la altura del entrepiso. La estructuración de los edificios es a base de marcos formadas por tres (o cuatro) crujías separadas por distancias de $6 \mathrm{~m}$ para edificios de 4 y 6 niveles, de $8 \mathrm{~m}$ para edificios de 8 y 10 niveles, y de $10 \mathrm{~m}$ para edificios de 15 y 20 niveles. Para todos los casos se considera una altura de entrepiso de $4 \mathrm{~m}$. El sistema de piso es a base de losa maciza. Se considera que las estructuras son regulares. Las características geométricas generales en planta y elevación se muestran en las figs. 3a y 3b, respectivamente.

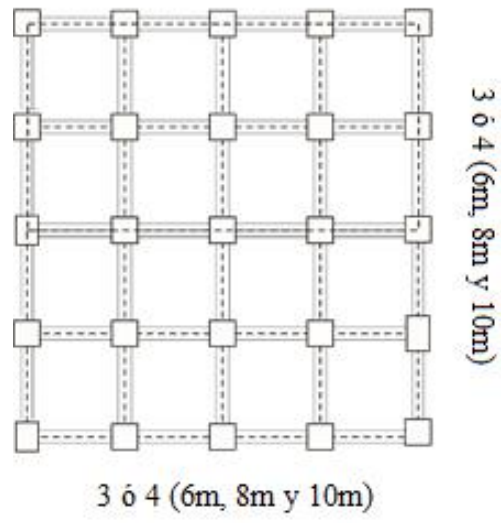

a)

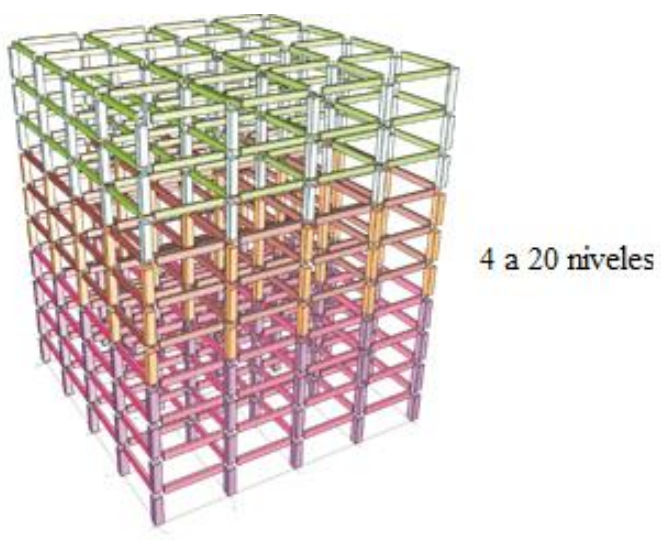

b)

Figura 3. Planta y elevación de los edificios de C/R analizados 


\section{Edificios de acero}

Paralelamente se analizan 7 edificios de acero de 4, 6, 8, 10, 12, 15 y 20 niveles. Los edificios de 4 a 10 niveles tienen 3 crujías, y los edificios de 12 a 20 niveles tienen 4 crujías. Para el diseño de los edificios se utilizó un factor de comportamiento sísmico $\mathrm{Q}=3$. Las distorsiones de entrepiso se limitaron a $\delta / \mathrm{h}=$ 0.015 para colapso, y $\delta / \mathrm{h}=0.004$ para servicio, donde $\delta$ es el desplazamiento y h la altura del entrepiso.

La estructuración de los edificios es a base de marcos de acero formados por tres (o cuatro) crujías separadas por distancias de $6 \mathrm{~m}$ para edificios de 4 y 6 niveles, de $8 \mathrm{~m}$ para edificios de 8 y 10 niveles, y de $10 \mathrm{~m}$ para edificios de 15 y 20 niveles. Para todos los casos se considera una altura de entrepiso de $4 \mathrm{~m}$. Se considera que las estructuras son regulares. Para rigidizar la estructura se utilizaron contravientos concéntricos ubicados en la crujía central para los edificios más bajos (de 4 a 10 niveles), y en las dos crujías de los extremos para los edificios más altos (de 12 a 20 niveles). Las características geométricas generales en planta y elevación de los modelos se muestran en las figs. 4 y 5.

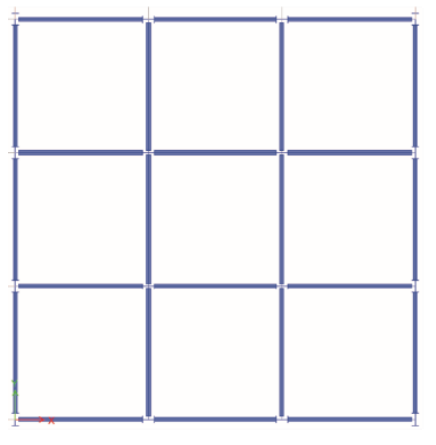

$3(6 \mathrm{~m}$ ó $8 \mathrm{~m})$

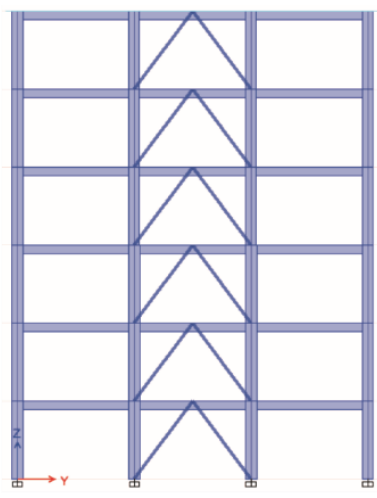

4 a 10 niveles

Figura 4. Planta y elevación de los edificios de acero analizados de 4 a 10 niveles

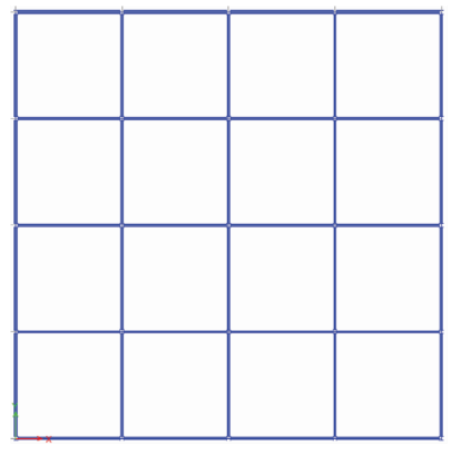

$4(8 \mathrm{~m}$ ó $10 \mathrm{~m})$

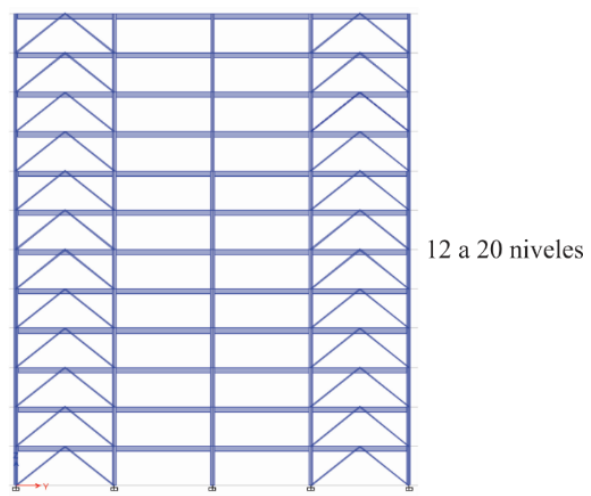

Figura 5. Planta y elevación de los edificios de acero analizados de 12 a 20 niveles

\section{Especificaciones de análisis y diseño estructural}

El diseño de los edificios se lleva a cabo de acuerdo con los criterios del Reglamento de Construcciones del Distrito Federal (2004). En las combinaciones de diseño se emplean los factores de carga 
muerta $\left(F_{C M}\right)$, de carga viva instantánea $\left(F_{C V}\right)$ y de sismo $\left(F_{C S}\right)$. En la tabla 4 se muestran las distintas combinaciones utilizadas, haciendo notar que la combinación 1 es la que recomienda el RCDF-2004.

\section{Modelación de las estructuras}

En este estudio se utilizan los análisis dinámicos incrementales para determinar el comportamiento y capacidad estructural en el ambiente sísmico de los edificios diseñados ante distintas combinaciones. Para ello, se desarrollan modelos tridimensionales representativos de la estructura en el software Ruaumoko3D (Carr, 2007). En estos modelos se supone que las losas proporcionan un diafragman rígido. Además, en estos análisis se considera degradación de rigidez y resistencia de los elementos de concreto reforzado. Para la degradación de rigidez se utiliza el modelo de Takeda Modificado (Otani, 1974).

Tabla 4. Combinaciones de carga

\begin{tabular}{cccc}
\hline Combinación & $\mathrm{F}_{\mathrm{CM}}$ & $\mathrm{F}_{\mathrm{CV}}$ & $\mathrm{F}_{\mathrm{CS}}$ \\
\hline $\mathbf{1}$ & $\mathbf{1 . 1}$ & $\mathbf{1 . 1}$ & $\mathbf{1 . 1}$ \\
2 & 1 & 1 & 1 \\
3 & 1 & 1 & 1.1 \\
4 & 1 & 1 & 1.2 \\
5 & 1.1 & 1 & 1.2 \\
6 & 1.2 & 1 & 1 \\
7 & 1.2 & 1 & 1.1 \\
8 & 1.2 & 1 & 1.2 \\
9 & 1.1 & 1 & 1 \\
10 & 1.1 & 1 & 1.1 \\
11 & 1.1 & 1.1 & 1.2 \\
\hline
\end{tabular}

\section{EJEMPLO DE APLICACIÓN}

En esta sección se aplican los pasos descritos en la metodología a los edificios de $\mathrm{C} / \mathrm{R}, \mathrm{y}$ posteriormente se aplican a los edificios de acero. A continuación, se muestran los resultados obtenidos correspondientes a un edificio de 10 niveles de C/R.

\section{Curvas de peligro de demanda estructural}

Conociendo la curva de peligro sísmico para el periodo fundamental de vibrar de la estructura de interés, y utilizando la ec. 1, se puede obtener la curva de peligro de demanda de distorsión máxima de entrepiso que representa las tasas medias anuales de excedencia de $d$. En las fig. 6 se muestran las curvas de peligro de demanda para el edificio de $\mathrm{C} / \mathrm{R}$ diseñado con las distintas combinaciones de carga establecidas en la tabla 4 y que se indican en el gráfico usando la palabra Combo, la nomenclatura, M10-3, se refiere a un edificio de 10 niveles de altura y tres crujías en cada dirección. En la fíg. 6 se observa que para distorsiones máximas de entrepiso pequeñas la diferencia de $v_{D}(d)$ entre cada diseño es pequeña, esto se debe a que para estos niveles de intensidad la estructura permanece elástica; sin embargo, a partir de cierto nivel de intensidad, la diferencia se incrementa. 


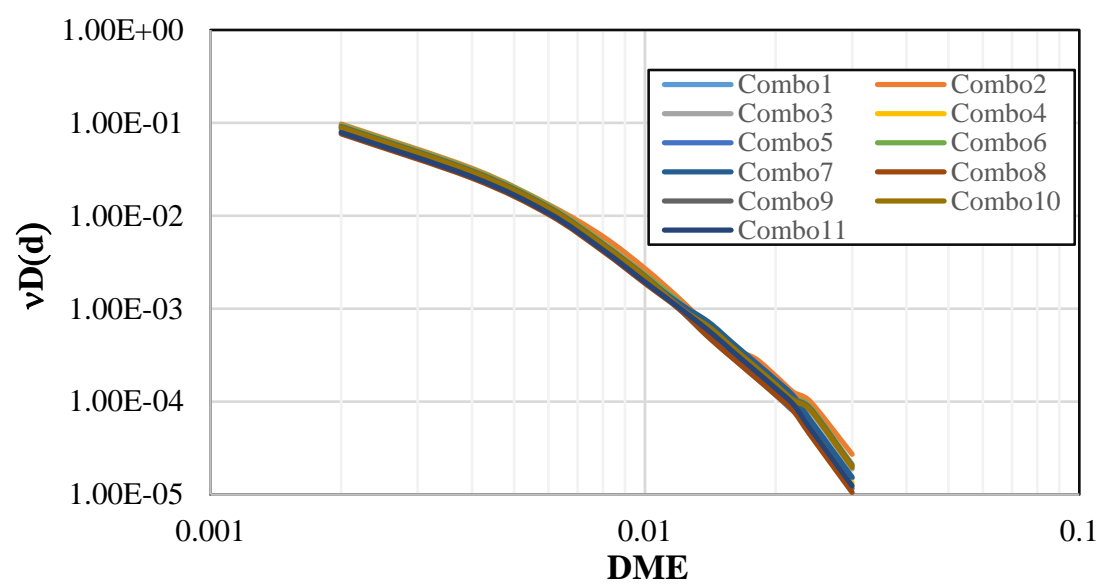

Figura 6. Curvas de peligro de demanda para el marco M10-3

\section{Curvas de capacidad estructural}

En lo que sigue se aplican los pasos descritos en la sección 3.4 primeramente a un edificio de diez niveles y tres crujías en ambas direcciones (M10-3), y posteriormente a todos los edificios de C/R ubicados en la Zona IIIb. El edificio tiene un periodo fundamental de vibración de $1.25 \mathrm{seg}$. Con base en los ADI's se obtiene la mediana y la desviación estándar del logaritmo de la capacidad máxima, así como también la mediana y la desviación estándar del logaritmo de la capacidad de fluencia para cada una de las combinaciones estudiadas. La fig. 7 muestra la pseudoaceleración vs las distorsiones máximas de entrepiso correspondientes al marco M10-3, para cada uno de los 31 registros considerados. La fig. 7 corresponde al diseño obtenido con la combinación 1. En la tabla 5 se presentan los valores de las medias logarítmicas del ajuste de curvas para la capacidad de colapso y de fluencia así como también sus respectivas desviaciones estándar logarítmicas, correspondientes a las 11 combinaciones (combo) que se indican en la tabla 4.

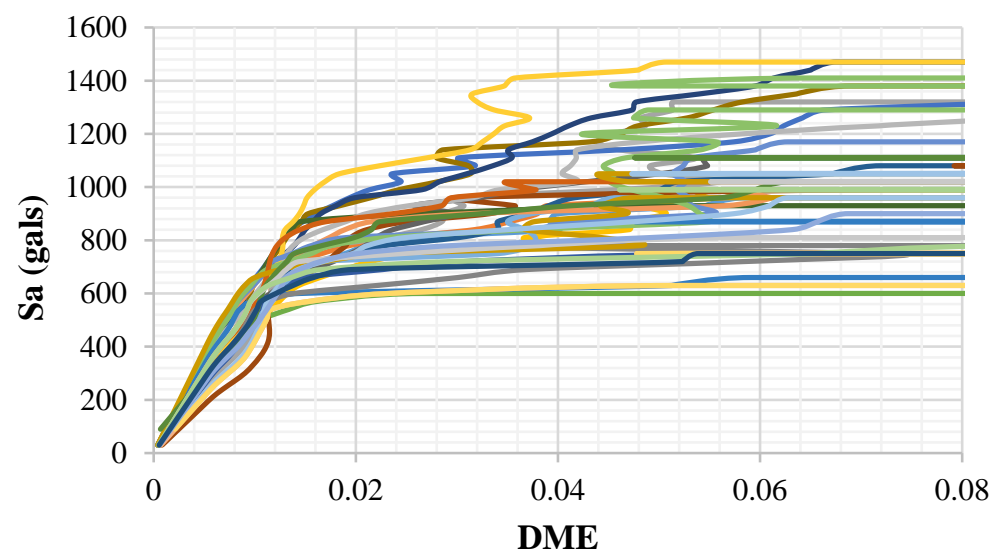

Figura 7. ADI's para el marco M10-3 de C/R 
Tabla 5. DME para los estados límite de colapso y de fluencia para el marco M10-3

\begin{tabular}{ccccc}
\hline $\begin{array}{c}\text { Combinación } \\
\text { (Combo) }\end{array}$ & \multicolumn{2}{c}{ Colapso } & \multicolumn{2}{c}{ Fluencia } \\
\hline 1 & 0.0308 & 0.18 & 0.0082 & 0.08 \\
2 & 0.0323 & 0.23 & 0.0077 & 0.082 \\
3 & 0.0325 & 0.21 & 0.0079 & 0.089 \\
4 & 0.0338 & 0.19 & 0.0083 & 0.091 \\
5 & 0.0341 & 0.2 & 0.0083 & 0.078 \\
6 & 0.0325 & 0.22 & 0.0077 & 0.083 \\
7 & 0.0352 & 0.24 & 0.0082 & 0.085 \\
8 & 0.0319 & 0.19 & 0.0084 & 0.09 \\
9 & 0.0293 & 0.2 & 0.0077 & 0.083 \\
10 & 0.0322 & 0.19 & 0.0082 & 0.086 \\
11 & 0.034 & 0.22 & 0.0079 & 0.087 \\
\hline
\end{tabular}

\section{Simulación de la demanda estructural}

A partir de la curva de peligro de demanda de distorsión se simulan las demandas sísmicas. La simulación se realiza mediante el método de simulación inversa. Se supone que los tiempos de ocurrencia están gobernados por procesos de Poisson y, por tanto, los intervalos de tiempo de espera de las demandas estructurales siguen una distribución exponencial. Se realiza un análisis temporal de demandas considerando una vida útil de la estructura de 50 años. El número de eventos al año se ajusta al número promedio de eventos registrados en la Base de Datos de Sismos Mexicanos (SMIS-2015). En promedio se esperan tres eventos por año con una magnitud igual o mayor que 6.0. En la fig. 8 se muestran las demandas estructurales simuladas de DME correspondientes al marco M10-3 diseñado con la combinación 1.

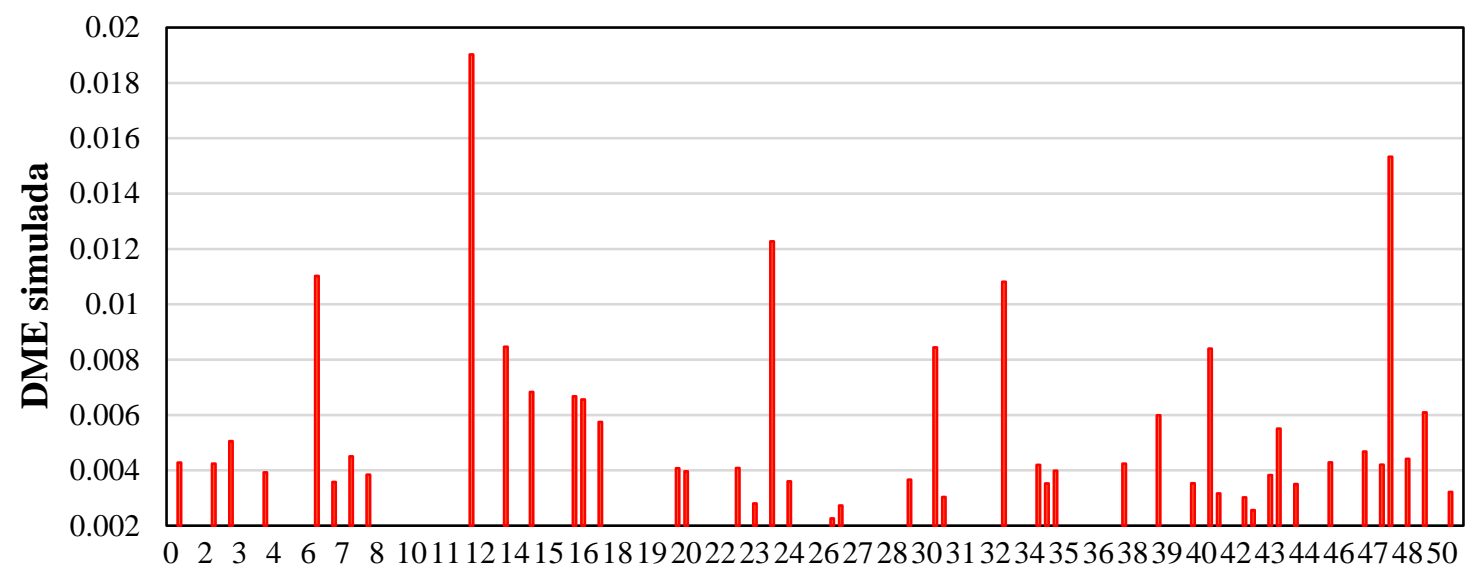

Años

Figura 8. DME simuladas a partir de la curva de peligro de demanda del marco M10-3 


\section{Costo total asociado a la vida útil}

A partir de la cantidad de material (concreto y acero) correspondiente al edificio de 12 niveles diseñado con la combinación 1 , se aplicó la ec. 10 para obtener el costo inicial $\mathrm{C}_{\mathrm{i}}=29.60$ millones de pesos (mdp).

Por otra parte, el costo de reparación por daños y los costos sociales que ocurren durante la vida útil de la estructura, se estima a partir de las distorsiones máximas de entrepiso simuladas. En la fig. 9 se muestran estos costos debido a las demandas estructurales evaluadas en cada instante de tiempo durante la vida útil de la estructura, debidamente transportados al valor presente del dinero (ec. 20). En este estudio se supone una tasa de interés anual del $5 \%$.

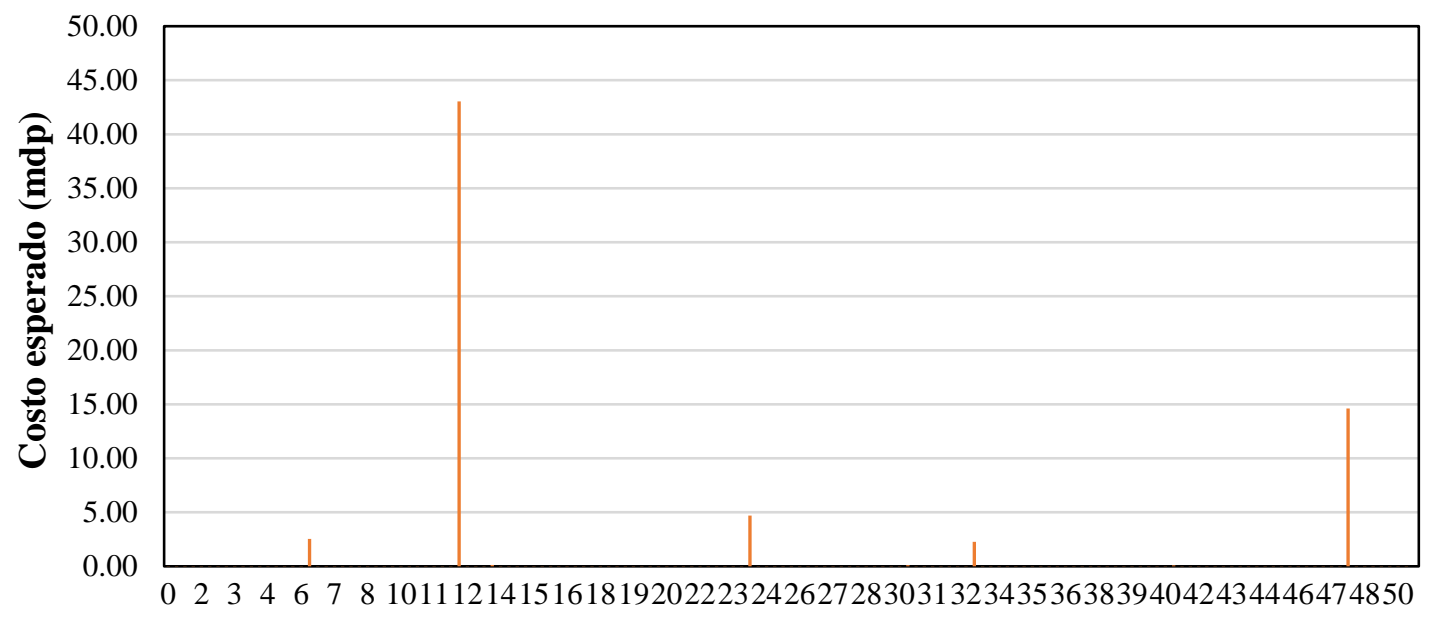

Años

Figura 9. Costo generado durante la vida útil del edificio M10-3, Combo 1

El costo de reparación por daños y los costos sociales durante la vida útil de la estructura se obtiene de la suma de los costos generados en cada instante de tiempo (fig. 9). El costo total (ec. 4) para el escenario simulado de demandas estructurales que se muestra en la fig. 9 se obtiene al sumar el costo inicial $\left(\mathrm{C}_{\mathrm{i}}\right)$, el costo de reparación por daños $\left(C_{d}\right)$ y los costos sociales $\left(C_{s}\right)$ resultando $C_{t}=88.18$ mdp.

El costo total previamente obtenido corresponde únicamente al considerar la simulación de un solo escenario de demandas estructurales sísmicas; sin embargo, como resultado final se toma el valor medio de los costos totales que resulta de evaluar 100 simulaciones de escenarios de demandas estructurales sísmicas para una misma combinación de carga $(\gamma)$. El procedimiento anterior se aplica a cada uno de los diseños obtenidos usando las diferentes combinaciones de carga. El resumen del costo total esperado se muestra en la tabla 6. Las combinaciones 2, 3 y 9 no cumplen con la restricción de la probabilidad de falla mínima por lo que no se incluyen en la tabla 6 . En esta misma se indica la tasa de falla estructural $\left(v_{f}\right)$ y su correspondiente periodo de retorno. En la tabla 6 se puede observar que el costo mínimo asociado a la estructura M10-3 corresponde a la combinación 8 (Combo 8), el cual es $21 \%$ menor que el costo que se obtiene si el edificio se diseña con la combinación especificada en el RCDF-2004 (combo 1). 
Tabla 6. Costo total esperado durante la vida útil del edificio M10-3 correspondiente a diferentes combinaciones de factores de carga

\begin{tabular}{ccccc}
\hline Combinación & $\begin{array}{c}\text { Costo total } \\
(\mathrm{mdp})\end{array}$ & $\begin{array}{c}\$ / \mathrm{m} 2 \\
(\text { pesos })\end{array}$ & $v_{f}$ & $\begin{array}{c}\text { Periodo de } \\
\text { retorno } \\
\text { (años) }\end{array}$ \\
\hline Combo 1 & 88.18 & 15308.74 & 0.001305 & 766.3 \\
Combo 4 & 76.53 & 13286.19 & 0.00124 & 806.5 \\
Combo 5 & 73.83 & 12817.09 & 0.00123 & 813 \\
Combo 6 & 92.00 & 15973.08 & 0.00129 & 775.2 \\
Combo 7 & 83.75 & 14539.60 & 0.00128 & 781.3 \\
Combo 8 & $\mathbf{7 0 . 2 2}$ & $\mathbf{1 2 1 9 0 . 3 1}$ & $\mathbf{0 . 0 0 1 2}$ & $\mathbf{8 3 3 . 3}$ \\
Combo 10 & 90.38 & 15690.36 & 0.001296 & 771.6 \\
Combo 11 & 70.77 & 12287.25 & 0.00122 & 819.7 \\
\hline
\end{tabular}

\section{SIMULACIÓN DE EDIFICIOS UTILIZANDO REDES NEURONALES ARTIFICIALES}

Con el fin de evaluar la ec. 7 (considerando todos los edificios ubicados en la zona sísmica de interés) se hace uso de la teoría de Redes Neuronales Artificiales.

Con la base de datos de los edificios diseñados se desarrollaron dos modelos de RNA y sus respectivos programas de cómputo que permiten realizar el diseño sísmico de edificios que se encuentran ubicados en la Zona IIIb del valle de México. El primer programa proporciona las dimensiones y las cuantías de refuerzo para edificios de 3 a 20 niveles de tal forma que es posible simular edificios ubicados en esta zona en un intervalo de tiempo muy corto (Bojórquez et al., 2014, 2016). Además, también se desarrolló un modelo de RNA que permite estimar tanto la capacidad estructural como la curva de demanda de los edificios simulados con el primer programa. Con estas herramientas se hace la simulación de toda la zona sísmica obteniendo un mapa de costos totales de edificios ubicados en la Zona IIIb. Se obtiene la combinación de carga óptima haciendo la minimización del costo total durante la vida útil de los edificios. Para este caso se simularon de forma aleatoria los edificios que se indican en la fig. 2.

\section{Resultados del conjunto de edificios}

Con el fin de analizar la influencia del periodo fundamental de las estructuras en los factores correspondientes a la combinación óptima de carga, en lo que sigue se separan los modelos estructurales por intervalos en función de su periodo fundamental de vibración (T). Los intervalos considerados se muestran en la tabla 7:

Tabla 7. Intervalos de periodo fundamental de vibración

\begin{tabular}{c}
\hline Intervalo $(\mathrm{seg})$ \\
\hline $0.3<\mathrm{T} \leq 0.8$ \\
$0.8<\mathrm{T} \leq 1.3$ \\
$1.3<\mathrm{T} \leq 1.8$ \\
$1.8 \leq \mathrm{T}$ \\
\hline
\end{tabular}


Los resultados de los costos totales esperados y las tasas de falla del conjunto de todos los edificios ubicados en la Zona IIIb de la Ciudad de México son resumidos en la tabla 8, en dicha tabla se muestran el resumen de resultados del promedio de 100 simulaciones de demandas estructurales, se observa que la combinación 10 tiene el menor costo total esperado, el cual es $2 \%$ más pequeño que el de la combinación 1; sin embargo, la tasa de falla de la combinación 1 es ligeramente mayor que la de la combinación 10. De los resultados no mostrados se observó que los costos son similares para los edificios altos cuando se incrementa el factor por carga muerta $\left(F_{C M}\right)$ sin modificar el factor por sismo $\left(F_{C S}\right)$; a diferencia de lo que ocurre con los edificios con periodos fundamentales de vibración pequeños en donde se observó que al incrementar el $F_{C M} \sin$ modificar el $F_{C S}$ los costos presentan variaciones más grandes, debido a que en estos casos las cargas gravitacionales influyen más en el diseño. Los edificios más vulnerables ante sismo en la Zona IIIb se encuentran en los intervalos segundo y tercero, es decir edificios que tienen periodos fundamentales entre 0.8 y 1.8 segs.

$\underline{\text { Tabla 8. Costos totales para todo el conjunto de edificio (C/R y acero) }}$

\begin{tabular}{ccccc} 
Combinación & $\begin{array}{c}\text { Costo Total } \\
(\mathrm{mdp})\end{array}$ & $\begin{array}{c}\$ / \mathrm{m} 2 \\
(\mathrm{pesos})\end{array}$ & $v_{f}$ & $\begin{array}{c}\text { Periodo de } \\
\text { retorno }\end{array}$ \\
\hline Combo 1 & $\mathbf{2 2 9 6 . 4 9}$ & $\mathbf{7 9 9 7 . 4 1}$ & $\mathbf{0 . 0 0 0 5 1 8 4}$ & $\mathbf{1 9 4 7 . 8 2}$ \\
Combo 4 & 2486.57 & 8546.38 & 0.000486504 & 2055.48 \\
Combo 5 & 2453.23 & 8456.85 & 0.000467102 & 2140.86 \\
Combo 6 & 2407.77 & 8265.76 & 0.00050758 & 1970.13 \\
Combo 7 & 2376.41 & 8236.15 & 0.000505905 & 1976.66 \\
Combo 8 & 2484.90 & 8522.55 & 0.000494394 & 2022.68 \\
Combo 10 & $\mathbf{2 2 5 4 . 7 5}$ & $\mathbf{7 8 1 2 . 2 7}$ & $\mathbf{0 . 0 0 0 5 1 3 4}$ & $\mathbf{1 9 2 9 . 0 3}$ \\
Combo 11 & 2408.11 & 8320.89 & 0.000479823 & 2084.10 \\
\hline
\end{tabular}

\section{CONCLUSIONES}

Se propuso una metodología para optimizar los factores de carga para el diseño sísmico de edificios de concreto reforzado y acero ubicados en la Zona IIIb de la Ciudad de México y diseñados con el Reglamento de Construcción del Distrito Federal 2004. La combinación óptima de los factores de carga se obtuvo utilizando un análisis de confiabilidad estructural y técnicas de inteligencia artificial. El procedimiento fue minimizar el costo total esperado en la vida útil de los edificios, y que estos tengan una probabilidad anual de falla igual o menor a la implícita en diseños hechos de acuerdo con el Reglamento de Construcciones para el Distrito Federal vigente. Se encontró que los factores de carga muerta, viva y sismo son dependientes del periodo fundamental de vibración de los edificios. Los resultados se resumen como sigue:

\begin{tabular}{cc}
\hline Intervalo (seg) & Factores de carga \\
\hline $0.3<\mathrm{T} \leq 0.8$ & $\mathrm{FCm}=1.1, \mathrm{FCv}=1.0, \mathrm{FCs}=1.0$ \\
$0.8<\mathrm{T} \leq 1.3$ & $\mathrm{FCm}=1.1, \mathrm{FCv}=1.1, \mathrm{FCs}=1.2$ \\
$1.3<\mathrm{T} \leq 1.8$ & $\mathrm{FCm}=1.1, \mathrm{FCv}=1.1, \mathrm{FCs}=1.1$ \\
$\mathrm{~T}>1.8$ & $\mathrm{FCm}=1.1, \mathrm{FCv}=1.0, \mathrm{FCs}=1.1$ \\
Todo el conjunto & $\mathrm{FCm}=1.1, \mathrm{FCv}=1.0, \mathrm{FCs}=1.1$ \\
\hline
\end{tabular}


Para los parámetros estudiados en este trabajado se encontró que los factores de carga son independientes al costo por pérdida de vidas humanas. Los periodos de retorno de falla asociados a todos los rangos de periodos de vibración son de alrededor 2000años o más excepto para el segundo intervalo de periodos, el cual es del orden de 1000años.

Si únicamente se fuera a implementar una combinación de carga en el Reglamento de Construcción del Distrito Federal, se recomienda la siguiente combinación de los factores de carga para el diseño de edificios ubicados en la Zona IIIb.

$$
\mathrm{FCm}=1.1, \mathrm{FCv}=1.1, \mathrm{FCs}=1.2
$$

\section{AGRADECIMIENTOS}

Este trabajo formó parte del proyecto 287103 de Ciencia Básica del CONACYT titulado Nueva formulación para obtener factores óptimos de carga para el diseño sísmico de edificios, cuyo apoyo agradecen encarecidamente los autores. El primer autor agradece la Beca otorgada por CONACYT para los estudios de Posgrado.

\section{REFERENCIAS}

Aktas, E, F Moses y M Ghosn (2001), "Cost and safety optimization of structural design specifications", Reliability Engineering and System Safety, Vol. 73, No. 3, pp. 205-212. https://www.sciencedirect.com/science/article/pii/S0951832001000461

American Society of Civil Engineers. (2010), "Minimum design loads for buildings and others structures", American Society of Civil Engineers, ASCE, Reston, VA. https://ascelibrary.org/doi/book/10.1061/9780784412916

Ang, A H-S (2011), "Life-cycle considerations in risk-informed decisions for design of civil infrastructures", Structure and Infrastructure Engineering, Vol. 7, No. 1-2, pp. 3-9. http://dx.doi.org/10.1080/15732471003588239

Barone, G y D M Frangopol (2015), "Life-cycle maintenance of deteriorating structures by multi-objective optimization involving reliability, risk, availability, hazard and cost", Structural Safety, Vol. 48, pp. 40-50. http://dx.doi.org/10.1016/j.strusafe.2014.02.002

Base de Datos de Sismos Mexicanos, SMIS (2015), "Sociedad Mexicana de Ingeniería Sísmica”, A. C.

Bojórquez, E, R Chávez, A Reyes-Salazar, S E Ruiz y J Bojórquez (2017) “A new ground motion intensity measure IB". Soil Dynamics and Earthquake Engineering, Vol. 99, pp. 97-107. https://doi.org/10.1016/j.soildyn.2017.05.011

Bojórquez, J, D Tolentino, J Yunes y S E Ruiz (2014), "Diseño de edificios de concreto reforzado utilizando redes neuronales artificiales", XIX Congreso Nacional de Ingeniería Estructural, Puerto Vallarta, Jalisco.

Bojórquez, J, S E Ruiz, D Tolentino y E Bojórquez (2015), "Diseño de edificios de concreto reforzado utilizando RNA", Concreto y Cemento: Investigación y Desarrollo, editada por el IMCyC, Vol 7, No. 2, pp. 60-78.

Bojórquez, J, S E Ruiz, E Bojórquez y A Reyes-Salazar (2016), "Probabilistic seismic response transformation factors between SDOF and MDOF systems using artificial neural networks" Journal of Vibroengineering, Vol. 18, No. 4, pp. 2248-2262. DOI: 10.21595/jve.2016.16506 
Bojórquez, J, S E Ruiz, B Ellingwood, A Reyes-Salazar y E Bojórquez (2017), "Reliability-based optimal load factors for seismic design of buildings", Engineering and Structures, No. 151. pp. 527-539. https://doi.org/10.1016/j.engstruct.2017.08.046

Carr, A (2008), "RUAUMOKO inelastic dynamic analysis program", Department of Civil Engineering, University of Canterbury, Christchurch, Nueva Zelanda.

Chan, S, S E Ruiz y M Montiel (2005), "Escalamiento de acelerogramas y mínimo número de registros requeridos para el análisis de estructuras", Revista de Ingeniería Sísmica, No. 7, pp. 1-24.

Cornell, C A (1968), "Engineering seismic hazard analysis", Bulletin of the Seismological Society of America, Vol. 58, No.5, pp. 1583-1606.

Cornell, C A, F Jalayer, R O Hamburger y D A Foutch (2002), "The probabilistic basis for the 2000 SAC/FEMA steel moment frame guidelines", Journal of Structural Engineering, No. 128, pp. 526533.

De León, D (1991), "Integrating socio-economics in the development of criteria for optimal Aseismic design of R/C buildings", Tesis de Doctorado, Universidad de California.

De León, D, y Ang A H-S (1995), "A damage model for reinforced concrete buildings. Futher study with the Mexico city earthquake", Structural Safety and Reliability, Balkema Rotterdam, pp. 2081-2087.

Ellingwood, B R (1994a), "Probability-based codified design for earthquakes", Engineering Structures, Vol. 6, No. 7, pp. 498-506. http://dx.doi.org/10.1016/0141-0296(94)90086-8

Ellingwood, B R (1994b), "Probability-based codified design: past accomplishments and future challenges", Structural Safety, Vol. 13, No. 3, pp. 159-176. http://dx.doi.org/10.1016/0167-4730(94)90024-8

Esteva, L (1968), "Bases para la formulación de decisiones de diseño sísmico", Tesis de Doctorado, Facultad de Ingeniería, UNAM, México.

Esteva, L, D Campos y O Díaz-López (2011), "Life-cycle optimization in Earthquake Engineering", Structure and Infrastructure Engineering, Vol. 7, pp. 33-49. http://dx.doi.org/10.1080/15732471003588270

Gaceta Oficial del Distrito Federal (2004), "Normas Técnicas Complementarias para Diseño por Sismo", México, DF.

Gayton, N, A Mohamed, J D Sorensen, M Pendola y M Lemaire (2004), "Calibration mathods for reliabilitybased design codes", Structural Safety, Vol. 26, No. 1, pp. 91-121. http://dx.doi.org/10.1016/S01674730(03)00024-9

Granados, R (2015), “Comunicación personal”, México D.F.

INEGI (2015), "Instituto Nacional de Estadística y Geografía”, www.inegi.org.mx/

Informe del Instituto de Ingeniería, UNAM (1985), "Efectos de los sismos de septiembre de 1985 en las construcciones de la Ciudad de México", México.

Lagaros, N D (2007), "Life-cycle cost analysis of design practices for RC framed structures", Bulletin of Earthquake Engineering, Vol. 5, pp. 425-442. https://link.springer.com/article/10.1007/s10518$\underline{007-9038-1}$

Mitropoulou, C Ch, N D Lagaros y M Papadrakakis (2011), "Life-cycle cost assessment of optimally designed reinforced concrete buildings under seismic actions", Reliability Engineering and System Safety, Vol. 96, No. 10, pp. 1311-1331. https://doi.org/10.1016/j.ress.2011.04.002 
Montiel, M A y S E Ruiz (2007), "Influence of structural capacity uncertainty on seismic reliability of building structures under narrow-band motions", Earthquake Engineering and Structural Dynamics, Vol. 36, pp. 1915-1934. https://doi.org/10.1002/eqe.711

Normas Técnicas Complementarias para Diseño y Construcción de Estructuras de Concreto (2004), "Gaceta Oficial del Distrito Federal", 6 de octubre, México, D F, México.

Normas Técnicas Complementarias sobre Criterios y Acciones para el Diseño de Edificaciones. NTCCA. (2004), “Administración Pública del Distrito Federal”, Jefatura de Gobierno, México, D.F.

Otani, S (1974), "SAKE-A computer program for inelastic response of R/C frames to earthquakes", Structural Research Series, University of Illinois, Urbana, No. 413.

Reglamento de Construcciones para el Distrito Federal, RCDF. (2004), “Administración Pública del Distrito Federal", Jefatura de Gobierno, México, D.F.

Rubinstein, R Y (1981), "Simulation and the Monte Carlo Method", John Wiley and Sons, pp. 372.

Shome, N y A C Cornell (1999), "Probabilistic seismic hazard demand analysis of nonlinear structures", Reliability of Marine Structures Programs, Report No. RMS-35, Dept. of civil Eng., Stanford University, Stanford, CA.

Sorensen, J D, I B Kroon y M H Faber (1994), "Optimal reliability-based code calibration", Structural Safety, Vol. 15, No. 3, pp. 197-208. http://dx.doi.org/10.1016/0167-4730(94)90040-X

Surahman, A y K B Rojaniani (1983), "Reliability based optimum design of concrete frames", Journal of the Structural Division, ASCE, Vol. 109, No. 3, pp. 71-76.

Tokyo Metropolitan Government, (1985), "Report in the investigation of the earthquake in Mexico", junio de 1985.

Tolentino, D y S E Ruiz SE (2013), "Time intervals for maintenance of offshore structures based on multiobjective optimization", Mathematical Problems is Engineering, Vol. 2013; No. 125856. http://dx.doi.org/10.1155/2013/125856

Vamvatsikos, D y C A Cornell (2002), "The incremental dynamic analysis and its application to performance-based earthquake engineering", Proceedings of the 12th European Conference on Earthquake Engineering, Paper 479, Londres, UK. http://citeseerx.ist.psu.edu/viewdoc/summary?doi=10.1.1.456.3199

Velázquez, I, J Bojórquez, S E Ruiz y F García-Jarque (2015), “Costos iniciales de edificios de C/R en la zona IIIb considerando distintas combinaciones de factores de carga", XX Congreso Nacional de Ingeniería Sísmica, Acapulco, Gro.

Wang, J, D Huang, S Chang y Y Wu (2014), "New evidence and perspective to the poisson process and earthquake temporal distribution from 55,000 events around taiwan since 1900", Natural Hazards Review, $\quad$ ASCE, $\quad$ Vol. $15, \quad$ No. $\quad 1, \quad$ pp. $\quad 38-47$. https://ascelibrary.org/doi/10.1061/\%28ASCE\%29NH.1527-6996.0000110

Wen, Y K (2001), "Reliability and performance-based design”, Structural Safety, Vol. 23, No. 4, pp. 407 428. http://dx.doi.org/10.1016/S0167-4730(02)00011-5

Wen, Y K y Y J Kang (2001a), "Minimum building life-cycle cost design Criteria. I: Methodology”, Journal of Structural Engineering, ASCE, Vol. 127, No. 3, pp. 330-337.

Wen, Y K y Y J Kang (2001b), “Minimum building life-cycle cost design Criteria. II. Applications”, Journal of Structural Engineering, ASCE, Vol. 127, No. 3, pp. 338-346. 